\title{
KASS v.2.2. scheduling software for construction
}

\author{
Michat Krzemiński ${ }^{1, *}$ \\ ${ }^{1}$ Warsaw University of Technology, Faculty of Civil Engineering, Al. Armii Ludowej 16, 00-637 \\ Warsaw, Poland
}

\begin{abstract}
The paper presents fourth version of specialist useful software in scheduling KASS v.2.2 (Algorithm Scheduling Krzeminski System). KASS software is designed for construction scheduling, specially form flow shop models. The program is being dedicated closely for the purposes of the construction. In distinguishing to other used programs in tasks of this type operational research criteria were designed closely with the thought about construction works and about the specificity of the building production. The minimal time, the minimal slack of brigades, the minimal slacks of the chosen working brigade and costs of the transfer operation of working fronts are included in operational research criteria between work centers. It is possible to enter data into the program both by hand as well as to load the Excel from files, similarly is with results, they are presented onscreen as well as a possibility of enrolling them in the file exists Excel. An element is very valid for it since allows for further simple processing of received results. In providing software for performing operational research calculations a technique of the complete review and simulation technology are being exploited. Described algorithms a program is using which will stay in the article as well as shown computational examples will remain.
\end{abstract}

\section{Introduction}

Construction scheduling problem is particularly important when the work accomplishment process is being prepared. Scheduling is a fast-growing area of scientific research in construction production engineering. It has applied methods of artificial intelligence, such as genetic algorithms, ant colony optimization algorithms, simulated annealing, neural networks. But also fuzzy logic techniques/elements of fuzzy logic are being widely used in order to determine time [1], [4].

This paper investigated a flow-shop scheduling problem, which consists in determining the optimum working sequence for brigades at workspaces. The model is based on assumptions that it is necessary to perform a sequence of technological operations, that the sequence is determined in advance and cannot be changed, that every brigade works at chosen workspace only once and at the exact time of its transition to another workspace, the next brigade comes in [7], [8].

* Corresponding author: $\underline{\text { m.krzeminski@,il.pw.edu.pl }}$ 
There is a lot of computer software which can help with scheduling process. Most popular are MS Project and Primavera. If we looking for software dedicated for flow shop models we can find programs like AIMMS - Flow Shop [9] and LEKIN -- Scheduling System [6]. These are very good and efficient programs but for mass production. For unique construction production we need something different. The construction has special conditions during production process so software need to have number of specified assessment criteria to give the best result. Answer for this problem may be KASS software.

\section{KASS v.2.2 program description}

The KASS v.2.2 software was written in the Java programming environment. It has a bilingual(Polish and English) interface, it does not require installation, it can be downloaded for free from the website www.ipb.edu.pl (bookmark - Programy).

The program uses the complete overhaul, when no more than 14 workspaces are considered. If there are more workspaces, the simulation was applied.

There are four optimization criterion: time, continuity, continuity of chosen brigade and brigade transition costs.

To show how the program works, we will use the example of optimization for chosen task. The picture below depicts the welcome window that appears after we start the program.

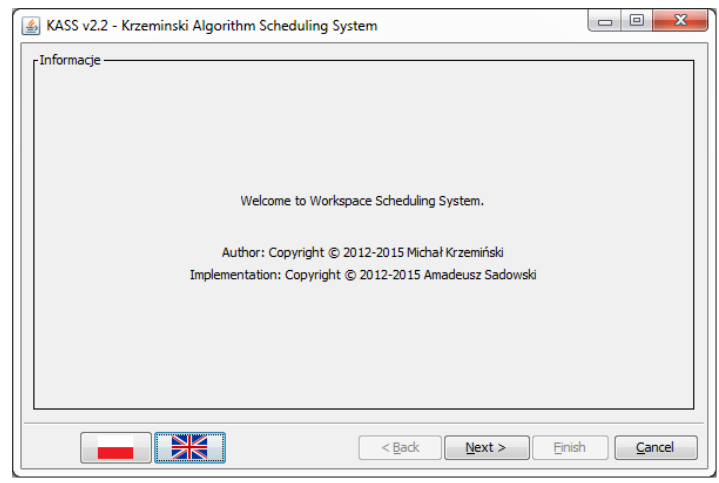

Fig. 1. The welcome window of the KASS v.2.2 program.

After we press the button Next, we move to the next window and we must choose workspace count (seven in this example), as well as working brigades count (four in this example).

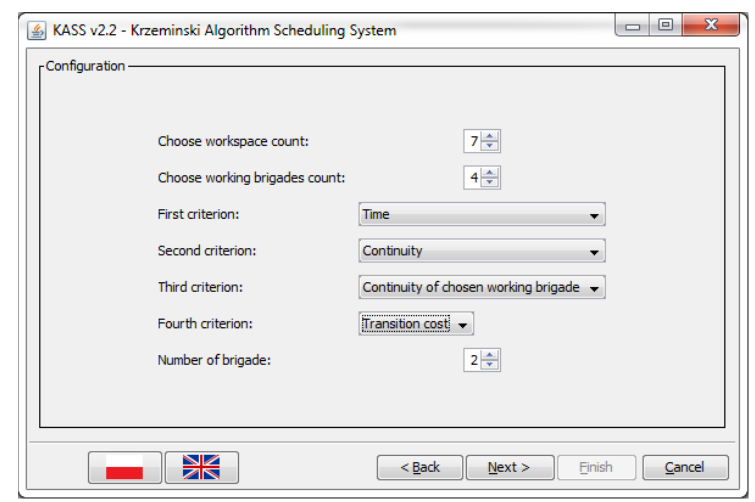

Fig. 2. The configuration window of the KASS v.2.2 program. 
It is also necessary to choose the assessment criteria which will be taken into account during optimization calculations. It is possible to choose from one to four criteria In this example shortest work accomplishment time was chosen as the main criterion, continuity is second criterion, continuity of the brigade number 2 is the third criterion and the lowest transition cots is the last criterion. The criteria sequence is important, as it sets its precedence. The first one will influence the most the results of optimization.

On the following pictures you can see two matrix . The first matrix should be completed with duration of activity on individual working plots. In the second matrix user need to enter the cost of teams transition between working plots. It is possible to load data from excel file.

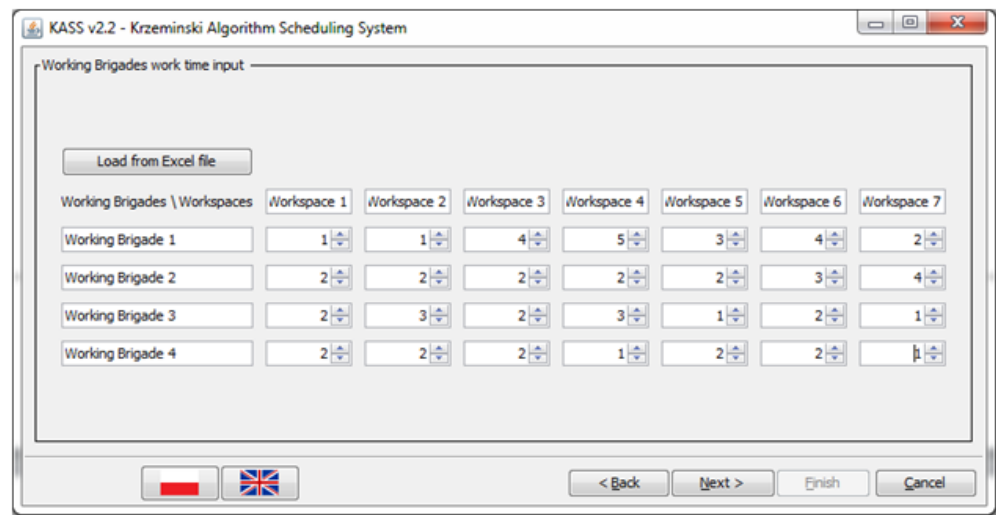

Fig. 3. Working time matrix.

The matrix of the transition costs don't need to be symmetrical. For example, equipment transport in up direction may be more expensive than transport in down direction.

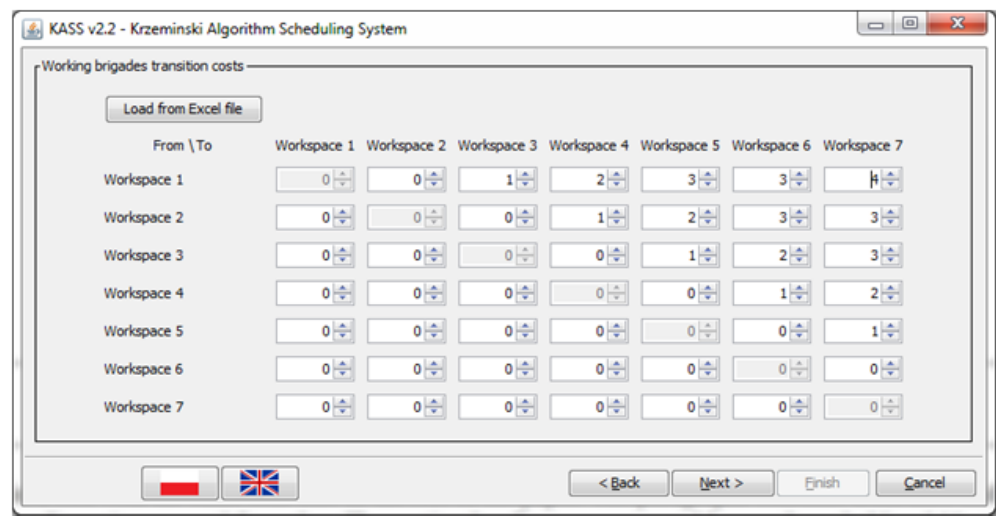

Fig. 4. Transitions costs matrix.

The last two picture number 5 and 6 depicts the results. The window presents the right scheduling and it is also possible to read off data concerning total time, total brigades work stoppages, chosen brigade work stoppage and brigades transition cost.

It is also possible to save the results as *.xlsx files, which are readable in the Excel program among others. It is useful, because it enables the KASS v.2.2. users to work further in an easy and comfortable manner on data that were obtained. 


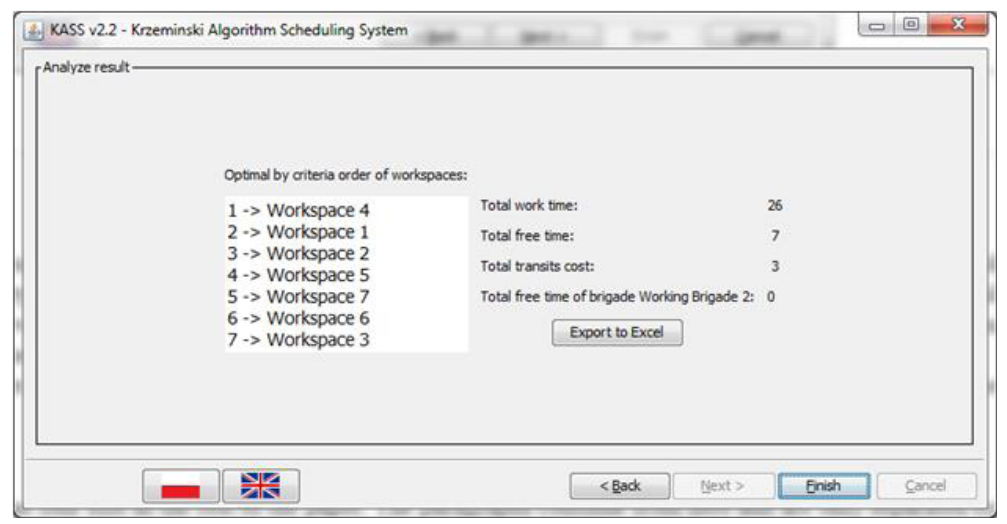

Fig. 5. The results window of the KASS v.2.2 program.

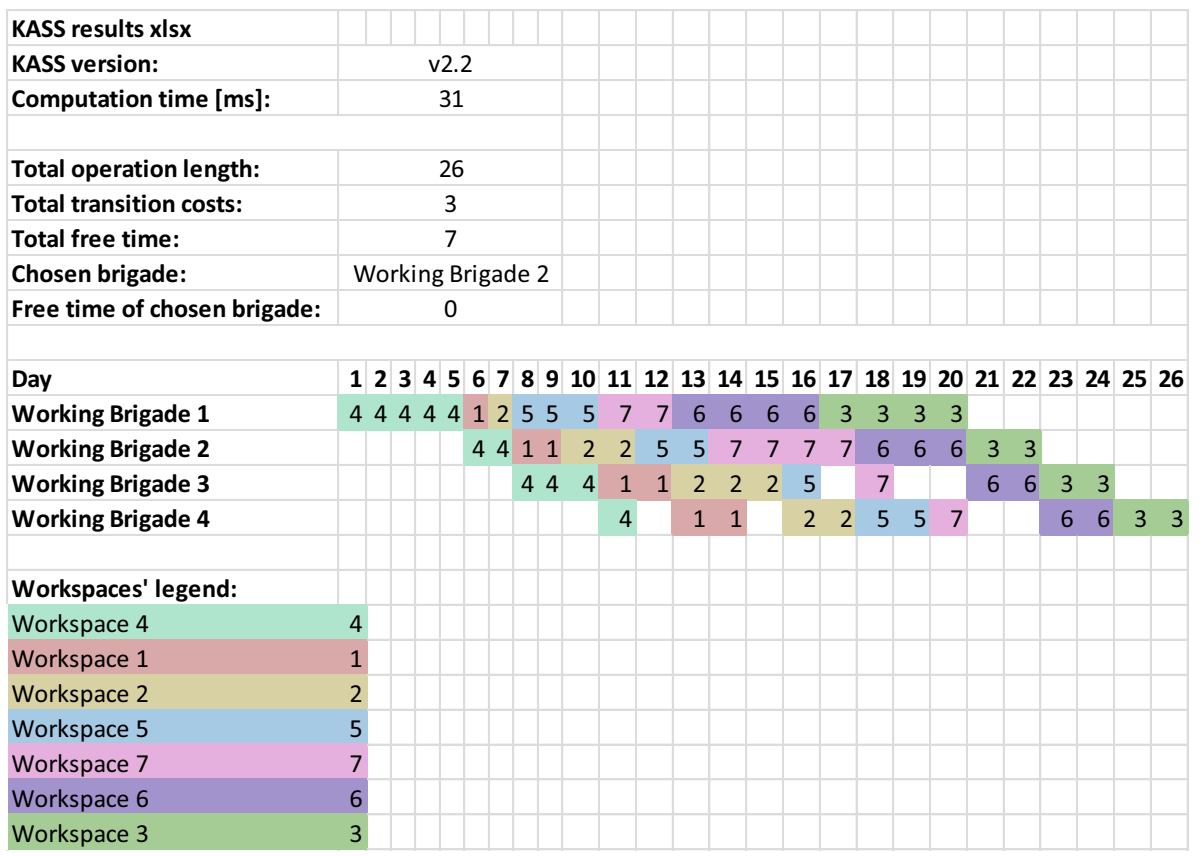

Fig. 6. The Excel results of the KASS v.2.2 program.

\section{Conclusions}

The article presents the latest version of the specialist software KASS. Software is dedicated for construction scheduling. Used assessment criteria and the possibility of cooperation with the MS Excel environment make program appropriate to support the real construction scheduling process. Previous versions of the software ware wildly tested. Tests were conducted for finishing works in the mall [3], for roadworks [5] and for monolithic construction works [2].

The author plans to work further on the KASS software and enlarge criteria, introduce heuristics, as well as elaborate the probabilistic version. 


\section{References}

1. N. Ibadov, J. Kulejewski, M. Krzemiński, Fuzzy ordering of the factors affecting the implementation of construction projects in Poland, AIP Conf. Proc. 1558, (2002)

2. P. Kowalik, M. Krzemiński, Logistyka NR 4, (2015)

3. M. Krzemiński M, E. Krasnodębska, Theor. Found. Of Civ. Eng. Polish-Ukrainian Trans. 22, (2014)

4. M. Krzemiński, AIP Conference Proceedings 1648, edited by T. Simos et al. (2015)

5. M. Krzemiński, A. Wypysiak, Scheduling complete review application for road works, Procedia Engineering 91 (2014)

6. A. Madureira, I. Pereira, N Sousa, P. Avila, J. Bastos, Comp. Intel. for Eng. Syst. 46, (2010)

7. M. L. Pinedo, Scheduling: Theory, Algorithms, and Systems (Springer, 2012)

8. M. L. Pinedo, Planning and Scheduling in Manufacturing and Services (Springer, 2009)

9. E. Zondervan, T. P. J. van Boekel, J. Fransoo, A. B. de Haan, Comp. Aid. Chem., Eng. (2014) 